\title{
A Comparative Study of Automated v/s Manual Measurement of Blood Pressure
}

\author{
Sanjay S. Pandarbale ${ }^{1}$, Celia Fernandes ${ }^{2}$ \\ ${ }^{1}$ Department of Physiology Goa Medical College, Bambolim, Goa, India. \\ ${ }^{2}$ Department of Physiology Goa Medical College, Bambolim, Goa, India.
}

\section{ABSTRACT}

\section{BACKGROUND}

Measurement of blood pressure accurately is imperative in the diagnosis and monitoring of a wide range of clinical conditions. The mercury sphygmomanometer discovered more than 100 years ago, has since been used as the gold standard to record blood pressure. Using the mercury sphygmomanometer requires adequate training and practice, whereas the automated devices are convenient and easier to use. We wanted to compare the readings taken by the manual mercury and the digital sphygmomanometer and determine the variations in the readings if any.

\section{METHODS}

This cross-sectional study was done in 148 apparently healthy medical students (males $n=58$, females $n=90$ ) (Fig. 1). Written informed consent was taken and the procedure was carried out. Questionnaires were provided to obtain demographic data from students. Blood pressure was recorded in the dominant arm using Pulse Wave 300 NISCO mercury sphygmomanometer, and OMRON HEM-7130 digital sphygmomanometer in the sitting, standing and recumbent posture. Three readings were recorded in each position with an interval of 2 mins., between each recording. The mean of the systolic and diastolic blood pressured was compared between the mercury and digital sphygmomanometer for variations if any. Data was analyzed using IBM SPSS version 22. P value of $\leq 0.05$ was considered significant.

\section{RESULTS}

In our study out of the 148 participants 58 were males and 90 were females. The overall mean systolic blood pressure recorded using the mercury sphygmomanometer was found to be $107.59 \pm 11.62 \mathrm{mmHg}$; mean diastolic blood pressure was found to be $68.83 \pm 8.91 \mathrm{mmHg}$; overall mean systolic blood pressure recorded using the digital sphygmomanometer was found to be $107.72 \pm 13.36$ $\mathrm{mmHg}$ and overall mean diastolic blood pressure was found to be $71.4 \pm 9.62 \mathrm{mmHg}$.

\section{CONCLUSIONS}

In our study no statistically significant difference was found between the BP measurements recorded using the mercury and digital sphygmomanometer (Table. 1,2). Mercury sphygmomanometer still remains the gold standard in recording blood pressure, and those who are unskilled in recording BP using the standard method could utilize the digital device as it is easier and more convenient.

\section{KEY WORDS}

BP, Mercury Sphygmomanometer, Digital Sphygmomanometer
Corresponding Author: Dr. Sanjay S. Pandarbale, Associate Professor, Department of Physiology, Goa Medical College, Bambolim, Goa, India.

E-mail: drsanjayspandarbale@gmail.com

DOI: $10.14260 /$ jemds $/ 2020 / 546$

How to Cite This Article:

Pandarbale SS, Fernandes $C$, A comparative study of automated $\mathrm{v} / \mathrm{s}$ manual measurement of blood pressure. J Evolution Med Dent Sci 2020;9 (35):2511-2514, DOI: 10.14260/jemds/2020/546

Submission 22-05-2020,

Peer Review 17-07-2020,

Acceptance 25-07-2020,

Published 31-08-2020.

Copyright (C) 2020 JEMDS. This is an open access article distributed under Creative Commons Attribution License [Attribution 4.0 International (CC BY 4.0)] 


\section{BACKGROUND}

Hypertension has since long been known as the silent killer, in the modern world of increasing non communicable diseases. ${ }^{1}$ Hypertension is a risk factor for cardiovascular diseases and is associated with multisystemic complications and premature deaths. Early detection of hypertension is important for the management and to prevent complications. Accurate measurement of blood pressure is imperative in the diagnosis and monitoring of patients with high blood pressure. ${ }^{2}$ For more than 100 years the mercury sphygmomanometer has been used as the gold standard noninvasive method of measuring blood pressure. However, increase awareness about mercury toxicity and potential environmental concerns has led to the replacement of mercury sphygmomanometers with alternative sphygmomanometers. ${ }^{3}$ Changes in both SBP and DBP are common with change in the posture of the individual. Automated devices are noninvasive, easier and safe to use and monitor, results are automatically given, they are portable, easy to carry, highly useful in remote areas when medical facilities are not at hand, and also help to eliminate observer bias and decrease white coat hypertension in the individual. Though the mercury sphygmomanometer still remains the gold standard in recording blood pressure, and those who are unskilled in measuring BP using the standard method, they could utilize the digital device which is more easy and convenient after proper calibration and validation. Different results could be obtained using sphygmomanometers (instruments) of different company makes. Studies also differ, when done during different times and seasons and can give varied results. Very limited studies are available concerning the accuracy and reliability of automated BP monitors. ${ }^{4}$ Therefore present study was carried out to determine the reliability of automated BP measuring instruments and compare the readings taken by the manual mercury and the digital sphygmomanometer and to determine the variations in the readings (if any).

\section{METHODS}

A cross sectional study was undertaken after taking a convenient sample size of 148 apparently healthy first year MBBS students (males $\mathrm{n}=58$, and females $\mathrm{n}=90$ ) (Fig. 1). After taking written informed consent and approval from IEC from Goa medical college Bambolim, students were enrolled in the study. Questionnaires were provided to obtain demographic data from students. Inclusion criteria: Those who gave consent were included in the study.
Students with history of hypertension, cardiac diseases, endocrine disorders, obesity, and renal diseases were excluded from the study. Blood pressure recordings were taken in the afternoon from 2 PM to 5 PM. Subjects were given a rest of 5 minutes before recording the blood pressure. The subject was made to sit comfortably in a chair with the arm resting on a table which was kept at the level of the heart. The blood pressure was recorded in the dominant arm using the mercury sphygmomanometer (PULSE WAVE 300 NISCO) and digital sphygmomanometer (OMRON HEM - 7130), in the sitting, standing and in recumbent posture. Three readings were recorded in each position with an interval of 2 mins., between each recording. The mean of the systolic and diastolic blood pressured was compared between the mercury and digital sphygmomanometer to see for variations if any.

\section{Statistical Analysis}

Data was analyzed using IBM SPSS version 22 with $p$ value of $\leq 0.05$ was taken as significant.

\section{RESULTS}

In our study, out of the 148 participants, males were 58, and females were 90 ) i.e. $61 \%$ were females and $39 \%$ were males (Fig. 1).

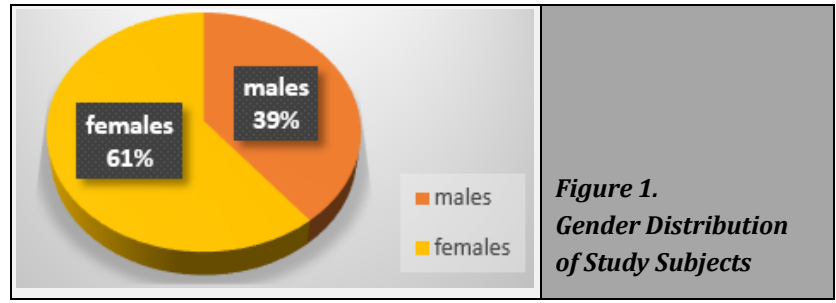

The mean SBP recorded in males using the mercury sphygmomanometer was found to be $115.91 \pm 11.06 \mathrm{mmHg}$, $115.08 \pm 10.81$ and $119.53 \pm 10.81 \mathrm{mmHg}$, and the mean DBP was found to be $69.67 \pm 8.43 \mathrm{mmHg}, 72.05 \pm 7.65 \mathrm{mmHg}$ and $71.93 \pm 6.70 \mathrm{mmHg}$ in sitting, standing and recumbent postures respectively. The mean SBP recorded using digital sphygmomanometer was found to be $115.09 \pm 10.39 \mathrm{mmHg}$, $117.91 \pm 11.93 \mathrm{mmHg}$ and $119.61 \pm 12.12 \mathrm{mmHg}$ and the mean DBP recorded was found to be to be $69.67 \pm 8.43 \mathrm{mmHg}, 72.05$ $\pm 7.65 \mathrm{mmHg}$ and $71.93 \pm 6.70 \mathrm{mmHg}$ in sitting, standing and recumbent postures respectively. The difference between mean SBP and DBP in males recorded using the two devices was not statistically significant (Table. 1).

\begin{tabular}{|c|c|c|c|c|c|c|c|c|c|c|c|c|}
\hline \multicolumn{7}{|c|}{ Systolic Blood Pressure } & \multicolumn{6}{|c|}{ Diastolic Blood Pressure } \\
\hline Posture & \multicolumn{2}{|c|}{ Sitting } & \multicolumn{2}{|c|}{ Standing } & \multicolumn{2}{|c|}{ Recumbent } & \multicolumn{2}{|c|}{ Sitting } & \multicolumn{2}{|c|}{ Standing } & \multicolumn{2}{|c|}{ Recumbent } \\
\hline Sphygmomanometer Type & Mercury & Digital & Mercury & Digital & Mercury & Digital & Mercury & Digital & Mercury & Digital & Mercury & Digital \\
\hline Mean Blood Pressure (mmHg) & 115.91 & 115.09 & 115.08 & 117.42 & 119.53 & 119.61 & 69.67 & 69.05 & 72.05 & 74.96 & 71.93 & 68.70 \\
\hline Standard Deviation & 11.06 & 10.39 & 10.8 & 11.93 & 10.81 & 12.12 & 8.43 & 10.29 & 7.65 & 9.47 & 6.70 & 7.01 \\
\hline Df & \multicolumn{6}{|c|}{56} & \multicolumn{6}{|c|}{56} \\
\hline P value & \multicolumn{2}{|c|}{4.65} & \multicolumn{2}{|c|}{0.61} & \multicolumn{2}{|c|}{0.95} & \multicolumn{2}{|c|}{2.64} & \multicolumn{2}{|c|}{0.66} & \multicolumn{2}{|c|}{3.57} \\
\hline & \multicolumn{2}{|c|}{ Not significant } & \multicolumn{2}{|c|}{ Not significant } & \multicolumn{2}{|c|}{ Not significant } & \multicolumn{2}{|c|}{ Not significant } & \multicolumn{2}{|c|}{ Not significant } & \multicolumn{2}{|c|}{ Not significant } \\
\hline
\end{tabular}




\begin{tabular}{|c|c|c|c|c|c|c|c|c|c|c|c|c|}
\hline \multicolumn{7}{|c|}{ Systolic Blood Pressure } & \multicolumn{6}{|c|}{ Diastolic Blood Pressure } \\
\hline Posture & \multicolumn{2}{|c|}{ Sitting } & \multicolumn{2}{|c|}{ Standing } & \multicolumn{2}{|c|}{ Recumbent } & \multicolumn{2}{|c|}{ Sitting } & \multicolumn{2}{|c|}{ Standing } & \multicolumn{2}{|c|}{ Recumbent } \\
\hline Sphygmomanometer Type & Mercury & Digital & Mercury & Digital & Mercury & Digital & Mercury & Digital & Mercury & Digital & Mercury & Digital \\
\hline Mean Blood Pressure (mmHg) & 103.03 & 97.09 & 103.11 & 101.54 & 108.80 & 105.57 & 62.95 & 62.25 & 66.99 & 69.01 & 67.43 & 66.44 \\
\hline Standard Deviation \pm & 9.69 & 10.48 & 9.29 & 13.15 & 9.65 & 10.78 & 8.961 & 8.08 & 6.64 & 9.61 & 8.36 & 9.44 \\
\hline Df & \multicolumn{6}{|c|}{90} & \multicolumn{6}{|c|}{90} \\
\hline P Value & \multicolumn{2}{|c|}{5.32} & \multicolumn{2}{|c|}{7.37} & \multicolumn{2}{|c|}{3.29} & \multicolumn{2}{|c|}{3.19} & \multicolumn{2}{|c|}{0.47} & \multicolumn{2}{|c|}{0.31} \\
\hline & \multicolumn{2}{|c|}{ Not significant } & \multicolumn{2}{|c|}{ Not significant } & \multicolumn{2}{|c|}{ Not significant } & \multicolumn{2}{|c|}{ Not significant } & \multicolumn{2}{|c|}{ Not significant } & \multicolumn{2}{|c|}{ Not significant } \\
\hline
\end{tabular}

The mean SBP recorded in Females using the mercury sphygmomanometer was $103.03 \pm 9.69 \mathrm{mmHg}, 103.11 \pm 9.29$ mmHg and $108.80 \pm 9.65 \mathrm{mmHg}$, and the mean DBP recorded was found to be $62.95 \pm 8.96 \mathrm{mmHg}, 66.99 \pm 6.64 \mathrm{mmHg}$ and $67.43 \pm 8.36 \mathrm{mmHg}$. The mean SBP recorded using digital sphygmomanometer was found to be $97.09 \pm 10.48 \mathrm{mmHg}$, $101.54 \pm 13.15 \mathrm{mmHg}$ and $105.57 \pm 10.78 \mathrm{mmHg}$ and the mean DBP recorded with the digital sphygmomanometer was found to be $62.25 \pm 8.08 \mathrm{mmHg}, 69.01 \pm 9.61 \mathrm{mmHg}$ and $66.94 \pm 9.44$ $\mathrm{mmHg}$ in sitting, standing, and recumbent posture respectively. The difference between mean SBP and DBP in females recorded using the two devices was not statistically significant (Table 2).

\section{DISCUSSION}

In our study, no statistically significant difference was found between the BP recording taken using the mercury and digital sphygmomanometer. As we know that for recording blood pressure we follow the indirect method and the principle is that it involves the balancing of pressure in a bag i.e. air pressure against the pressure of the blood in an artery. The air pressure is estimated by means of mercury sphygmomanometer. ${ }^{5}$ For recording blood pressure we used Omron Hem 7130 model of digital sphygmomanometer. Studies as per Jeyanthi $\mathrm{N}$ et al, that digital recording of blood pressure is based on the Oscillometric method.

There is electric pressure sensor which calculates BP. When the cuff is inflated with air so that the arteries get compressed and are narrowed and it does not allow blood to pass through the artery and when the pressure in the cuff pressure is released slowly it allows slow passage of blood and thus there will be vibration against the arterial wall and there will occurrence of cyclic expansion and contraction in the artery. And the point when the peak cyclic value reaches, is noted and with the help of generic algorithm the systolic and diastolic BP is calculated. The algorithms for each device vary. There is no standard algorithm in it. It has level indicator for the blood pressure and it can store up to 60 memories of data. Each data is displayed along with time and date. It also calculates average value of the last three data. Oscillometric apparatus translates arterial pressure in oscillometric wave and with system-built algorithm display readings.6,7 As per studies done by Ju Yang Chong et al in the Malaysian population it was seen that the SBP and DBP measurements of mercury and digital sphygmomanometer has a significantly high and moderate correlation respectively. ${ }^{8}$
Our study findings were also consistent with a study done by Wadhwani et al which stated that blood pressure readings obtained by automated and mercury sphygmomanometer are comparable however as compared to mercury sphygmomanometer oscillometric device gives slightly higher readings of SBP. ${ }^{9}$ No such discrepancy in readings was seen in our study. Similar studies done in Canadian population have also concluded that conventional manual mercury sphygmomanometers can be replaced by calibrated and validated automated devices. ${ }^{10}$ Our study findings differed from the studies done by Srinivasan et al and Bhatt et al which stated that BP measurements obtained using digital manometer significantly varied from the mercury manometer and showed higher levels of inaccuracy and therefore e should be used with extra caution in clinical settings.11,12 Variations in our study results could be due to type of instruments used and differences in study settings.

\section{CONCLUSIONS}

There is no significant variation in the blood pressure readings recorded with the manual mercury and automated digital sphygmomanometers. Since the systolic and diastolic blood pressure readings measured by manual mercury and digital devices were comparable, they can be used interchangeably in daily clinical practice. Automated devices are non-invasive, easier and safe to use and monitor. Results are automatically given, they are portable, easy to carry, highly useful in remote areas where medical facilities are not at hand. The digital sphygmomanometer eliminates observer bias and decreases white coat hypertension. Though the mercury sphygmomanometer still remains the gold standard in recording blood pressure, those who are unskilled in recording $\mathrm{BP}$ using the standard method could utilize the digital device as it is easier and more convenient after doing proper calibration and validation.

\section{Study Limitations and Future Recommendations}

1. Our study was limited to a sample size of 148 apparently healthy young adults, hence results of our study cannot be generalized to the entire population and so further studies with a larger sample size with different age groups should be undertaken.

2. The study was conducted using sphygmomanometers (instruments) from two different company makes (pulse wave mercury sphygmomanometer and Omron digital sphygmomanometer), different results could be obtained using sphygmomanometers (instruments) of different 
company makes, and hence extensive studies are needed to validate the accuracy of these instruments.

3. Our study was carried out during February and March (between 2 PM - 5 PM). Results can vary depending up on different times and seasons. Hence, future studies as needed to evaluate these seasonal and diurnal variations.

Financial or Other Competing Interests: None.

\section{REFERENCES}

[1] Sawicka K, Szczyrek M, Jastrzebska I, et al. Hypertension the silent killer. J Pre-Clinical and Clinical Research 2011;5(2):43-6.

[2] Shahbabu B, Dasgupta A, Sarkar K, et al. Which is more accurate in measuring the blood pressure? A digital or an aneroid sphygmomanometer. J Clin Diagn Res 2016;10(3):LC11-4.

[3] Shimek J, Emmanuel J, Orris P et al. Replacement of mercury thermometers and sphygmomanometers in health care: technical guidance. Geneva: World Health Organization 2011.

[4] Lim YH, Choi SY, Oh KW, et al. Comparison between an automated device and a manual mercury sphygmomanometer in an epidemiological survey of hypertension prevalence. Am J Hypertens 2014;27(4):537-45.

[5] Jain AK. Manual of practical physiology for MBBS. $5^{\text {th }}$ edn. Arya Publications (APC) 2016: p. 139.
[6] Jeyanthi N, Gokulnath BV, Thandeeswaran R. A walkthrough: complete survey on blood pressure monitoring devices and applications. Biomed Res 2018;29(21):375165.

[7] Kakkad KM, Damor P, Parmar B, et al. Comparative study of blood pressure measurement by aneroid and digital manual sphygmomanometer. National J Community Med 2016;7(8):700-2.

[8] Chong JY, Quek ZL, Thanapalan D, et al. Comparison between mercury manometer, digital device and aneroid device in blood pressure measurements. Public Health and Preventive Med 2018;4(2):35-43.

[9] Wadhwani R, Siddiqui NI, Sharma B. Assessment of accuracy of mercury sphygmomanometer and automated oscillometric device of blood pressure measurement in population of normal individuals. Asian J Med Sci 2018;9(5):17-24.

[10] Myers MG, McInnis NH, Fodor GJ, et al. Comparison between an automated and manual sphygmomanometer in a population survey. Am J Hypertens 2008;21(3):2803.

[11] Bhatt P, Arora S, Tamang E. Comparison of measurement accuracy of aneroid, digital and mercury sphygmomanometer. J Nursing Science Practice 2016;6(2):28-32.

[12] Srinivasan KM, Kumar KS, Saraswathi I, et al. Automated versus manual measurement of blood pressure. J Clin and Diagn Res 2018;12(8):CC09-2. 